\title{
APPLICATIONS OF CYTISINE EXTRACTION AND DETECTION IN BIOLOGICAL MATERIALS FOR CLINICAL MEDICINE
}

\author{
DOROTA BARTUSIK-AEBISHER ${ }^{1 *}$ DAVID AEBISHER ${ }^{2}$, RYAN J. COURTNEY ${ }^{3}$, \\ ANDRZEJ SOBCZAK ${ }^{4}$ ZUZẢNNA BOBER ${ }^{5}$, RAFAŁ PODGÓRSKI ${ }^{6}$, \\ PATRYCJUSZ KOŁODZIEJCZYK ${ }^{5}$ and PIOTR TUTKA ${ }^{1,3,5}$
}

${ }^{1}$ University of Rzeszów, Department of Experimental and Clinical Pharmacology, Faculty of Medicine, Al. Kopisto 2a, 35-959 Rzeszów, Poland

${ }^{2}$ University of Rzeszów, Department of Photomedicine and Physical Chemistry,

Faculty of Medicine, Warzywna 1a, 35-959 Rzeszów, Poland

${ }^{3}$ National Drug and Alcohol Research Centre, University of New South Wales, Sydney, NSW, Australia

${ }^{4}$ Medical University of Silesia, Department of General and Inorganic Chemistry,

School of Pharmacy with the Division of Laboratory Medicine,

Poniatowskiego 15, 40-055 Katowice, Poland

${ }^{5}$ University of Rzeszów, Centre for Innovative Research in Medical and Natural Sciences, Warzywna 1a, 35-959 Rzeszów, Poland

${ }^{6}$ University of Rzeszów, Department of Biochemistry, Faculty of Medicine, Warzywna 1a, 35-959 Rzeszów, Poland

\begin{abstract}
Tobacco use is a leading cause of preventable mortality worldwide. New cost-effective smoking cessation treatments are needed especially in some low-to-middle income countries where smoking rates are rising, and current pharmacotherapy treatments remain cost-prohibitive. Since the 1960's, cytisine has been used as an effective nicotine substitution agent to aid in smoking cessation albeit limited to a selected few Eastern/Central Europe and Central Asian countries. Cytisine is a biologically active alkaloid of plant origin and is known to be a ligand of nicotinic acetylcholinergic receptors (nAChRs). For several decades, the properties of cytisine have been investigated and reported in the biomedical and pharmaceutical literature. Due to the beneficial impact of cytisine on smoking cessation and its costly multistep synthesis, there is a growing interest in extraction from natural sources as well as in analytical identification and quantification for clinical medicine and forensic toxicology. In this paper, we present several current analytical approaches to cytisine extraction and identification from biological samples of plant and human origin. The development of extraction techniques will allow for the widespread use of the drug in experimental and clinical pharmacology, toxicology and forensic medicine.
\end{abstract}

Keywords: smoking cessation, cytisine extraction, biopharmacy, biomedicine, chromatography

Tobacco use causes 6 million deaths per year worldwide, and the World Health Organization (WHO) has projected that tobacco use will cause an additional 8 million deaths annually by 2030 (1). Recently, a comprehensive 187-country survey on the prevalence of daily smoking between 1980 to 2012 found a large reduction in smoking at a global level for both men and women. However, due to population growth, the number of daily smokers worldwide has significantly increased (2). Conse- quently, tobacco remains a significant threat to public health and intensified efforts to reduce smoking and promote cessation are needed. A recent editorial published in The Lancet stated that the current anti-tobacco strategy was failing. Subsequently, The Lancet commissioned "The World Without Tobacco in 2040" campaign (3). However, a trend analysis of the projected reduction in the number of cigarette smokers suggests that a tobacco-free world by 2040 may be ambitious (4). Based on medicinal reports,

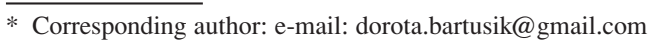


smokers die 10 years earlier than non-smokers albeit this time may be significantly decreased by quitting, especially before age 40 (5).

Despite attempts to control tobacco using a broad spectrum of interventions, breaking the nicotine habit remains very difficult. The best results in the treatment of nicotine addiction are achieved when a combination of pharmacotherapy and nonpharmacological treatments are used (6). However, despite their advantages, current pharmacotherapies are too expensive for many smokers, especially in low-to-middle income countries (LMICs), and are not widely disseminated to the general population of smokers. Therefore, there is an urgent need for alternative, more efficacious, safe and cheaper pharmacotherapies for health care systems and smokers. One such promising smoking cessation agent is the alkaloid cytisine ((-)-Cytisine, (1R,5S)-1,2,3,4,5,6Hexahydro-1,5-methano-8H-pyrido[1,2a][1,5]diazocin-8-one) which is a biologically active metabolite of plant origin known to be a ligand of nicotinic acetylcholinergic receptors (nAChRs). Despite its surprising popularity in some parts of the world, cytisine has been absent from almost all existing reviews of antismoking treatments. Recent highquality studies on the efficacy and safety of cytisine for smoking cessation established cytisine as a promising alternative to currently available smoking cessation drugs (7-10). Interest in the development of cytisine extraction and detection methodologies has been increasing due to its importance as a smoking cessation agent as well as the need for improved analytical methods for pharmacokinetics, measurements of clinical dosage, and toxicology.

\section{Pharmacological characteristics of cytisine}

Cytisine is a pyridine-like alkaloid (Fig. 1) that possesses promising pharmacological properties. As a potent drug, cytisine is involved in biological processes, specifically in binding to nAChRs (11). Cytisine is a partial agonist of the $\alpha_{4} \beta_{2} * \mathrm{nAChR}$ and a full agonist of receptors containing $\alpha 7$ and $\beta_{4}$ * (12). The $\alpha_{4} \beta_{2}{ }^{*}$ subtype of nAChRs mediates, at least partially and probably mainly, the rewarding and reinforcing effects of nicotine. Cytisine binds to

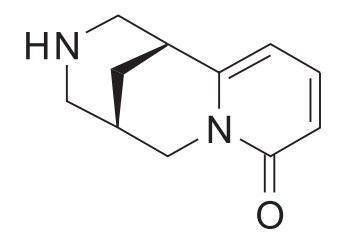

Figure 1. The structure of (-)-cytisine the $\alpha_{4} \beta_{2} \mathrm{nAChR}$ at nanomolar concentrations (12, 13) with $K_{i}$ values ranging from 0.45 to $2.4 \mathrm{nM}$ (14, 15) which are sufficient to activate these receptors even with limited blood-brain barrier penetration (14). Cytisine is thought to aid smoking cessation by reducing the severity of withdrawal symptoms (via its partial agonist action on $\alpha_{4} \beta_{2}{ }^{*} \mathrm{nAChR}$ ) and by reducing the reward and satisfaction associated with smoking (via antagonistic action against nicotine at $\alpha_{4} \beta_{2} *$ nAChR) (6).

Plasma concentrations of cytisine in humans have been reported in single-dose and during 25-day standard regimens by Jeong et al. (17-19). Cytisine was found to have a simple pharmacokinetic profile with maximum concentrations reached at $2 \mathrm{~h}$ postdose, and a half-life of $4.8 \mathrm{~h}$. During day 1 of the 25 day regimen, a plasma concentration of $50.8 \pm 4.7$ $\mathrm{ng} / \mathrm{mL}$ was measured suggesting a high oral bioavailability of cytisine (18). Cytisine remains intact from ingestion to elimination and no associated metabolites have been detected which reduces the potential for competitive inhibition of drug-metabolizing enzymes. To date, no drug-drug interactions with cytisine have been reported. Furthermore, even if cytisine is metabolized, its metabolites will be present in very low concentrations that are unlikely to be pharmacologically active. As a partial agonist of the $\alpha_{4} \beta_{2}{ }^{*} \mathrm{nAChR}$, cytisine exerts central and peripheral effects that resemble the effects of nicotine. Peripheral effects are manifested after administration of cytisine at doses that are $1 / 4$ to $2 / 3$ lower than the doses of nicotine required to cause the same effect (20). Cytisine administration at therapeutic doses does not appear to significantly affect blood pressure, heart rate or respiratory rate.

\section{Cytisine for smoking cessation}

Cytisine is considered to be the oldest medication used for smoking cessation $(8,21)$. Smoking cessation services providing behavioral support (e.g. face-to-face or telephone counseling) are effective but long-term quit rates remain too low (22). Alternatively, more than $80 \%$ of smokers using Nicotine Replacement Therapy (NRT), the most popular pharmacotherapy fail in their quit attempt (22). Cytisine has several advantages compared to existing smoking cessation pharmacotherapies including: (i) it has low cost being half to a twentieth the cost of other cessation drugs; (ii) it is welltolerated by smokers with a low rate of adverse events [21]; (iii) it is relatively inexpensive to produce) $(23,24)$; and (iv) importantly, it requires a shorter treatment period (i.e. 25 days) compared to 56 to 84 days for the nicotine replacements products, 


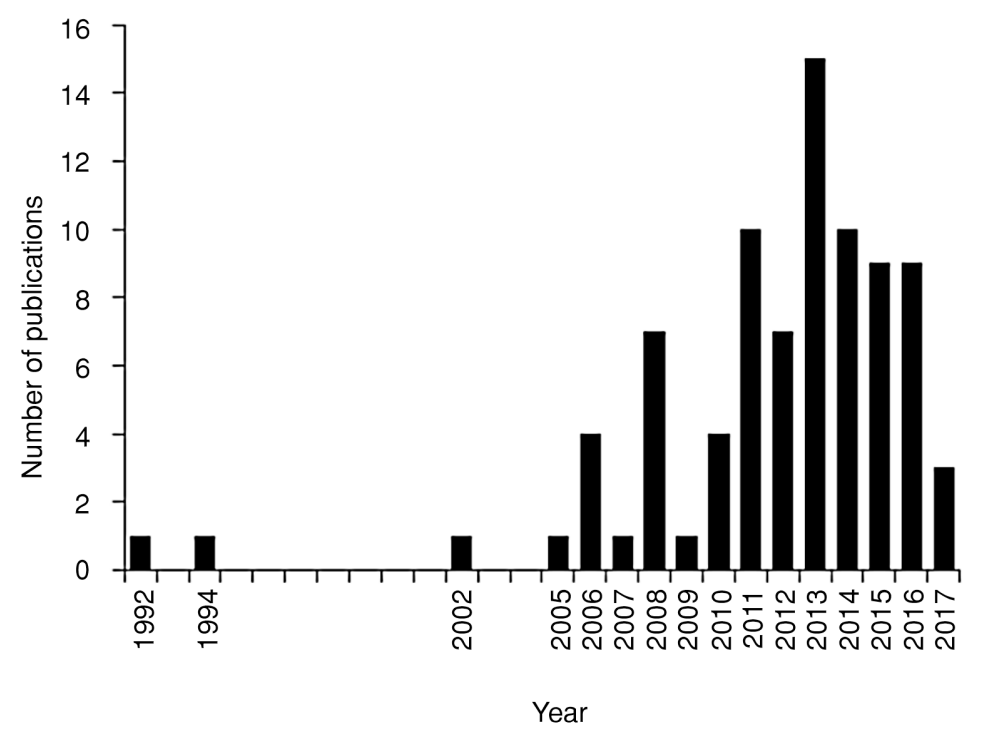

Figure 2. The number of articles published on cytisine per year from 1992 to present based on a search of PubMed

bupropion and varenicline $(23,24)$. A particular disadvantage was reported to be a higher incidence of gastrointestinal problems such as stomach aches which occurred more frequently in the cytisine group in comparison to placebo in a double-blind study (25).

Despite cytisine's long history as a smoking cessation aid $(21,24)$ most clinical studies were performed prior to the advent of good clinical practice (GCP) guidelines with only three placebo-controlled trials, and one pragmatic RCT compared to active treatment completed. Since the mid-2000s, however, there has been a resurgence and increased focus on cytisine for smoking cessation with recent clinical trial data demonstrating strong clinical evidence for both efficacy and safety endpoints (9). To date, only one pragmatic RCT (9) has tested cytisine's efficacy compared to another smoking cessation medication. Cytisine was only recently tested (2014) in a direct head-to-head trial against NRT in New Zealand $(n=1310)$ smokers $(9)$. It was found to be superior to nicotine patch for self-reported continuous abstinence rates at every follow-up ( 1 week $=$ $60 \%$ vs. $46 \% ; 2$ months $=40 \%$ vs. $31 \%$; and 6 months $=22 \%$ vs. $15 \%$ ).

Modeled evidence from a placebo-controlled trial (25) and a recent (2014) UK systematic review (26) suggests that health care systems globally could make substantial savings by offering cytisine instead of the NRT products bupropion and varenicline. Cytisine has been shown to have a lower cost per quality-adjusted life-year (QALY) than NRT but no comparison exists with varenicline $(21,27)$. Recent modeling suggests cytisine may produce substantial costs savings for global health care systems compared with current pharmacotherapies (28). This modeling relied on the results from one placebocontrolled trial (25) and the authors (along with a Health Technology Assessment commissioned by the NHS) concluded that confirmatory trials were necessary (28) to reduce uncertainty about costeffectiveness $(26,28)$. There is a need for further research testing cytisine's efficacy and safety against varenicline. Several new clinical trials are underway including two non-inferiority trials comparing cytisine to varenicline for smoking cessation in Australia ( $\mathrm{n}=1266$; smokers calling Quitline; standard 25-day course of Desmoxan ${ }^{\circledR}$ ) and New Zealand ( $\mathrm{n}=2140$; indigenous Mßori smokers; 12week course of Tabex) $(29,30)$. A further RCT is being conducted to assess cytisine's effects for smoking cessation among HIV-infected Russians (n $=400$ ) with heavy alcohol consumption and tobacco use (Russian RCT) (31). An RCT led by Siddigi and coworkers to evaluate cytisine use with and without behavioral support in tuberculosis patients is currently in progress (32). Another placebo-controlled, double-blind trial $(\mathrm{n}=567)$ of nortriptyline in comparison with cytisine is underway in Thailand (www.treattabacco.net). The findings from these trials will be vital for informing policymakers around the world and for wider global dissemination of cytisine. Relating to safety, evidence to date suggests that cytisine is as safe as other marketed smoking 
cessation medications e.g., NRT $(23,24)$. A recent systematic study concluded that cytisine, when used at its recommended dosage, does not increase adverse events (AEs) compared with placebo $(21 \%$ vs. $20 \%$ ), although there was some evidence of more gastrointestinal complaints (12\% vs. 7\%) (23). More, the recently completed head-to-head (cytisine vs NRT) New Zealand trial found a higher frequency of adverse events in the cytisine condition (288 events vs 174 events), although the majority of symptoms were non-serious, mild, and self-limiting (9). Among smokers in the cytisine group who reported an $\mathrm{AE}$; over $82 \%$ stated they would still recommend cytisine to a smoker who wanted to quit (9). Currently, there is no direct evidence to draw firm conclusions on cytisine's safety compared to varenicline, albeit clinical evidence and trial recruitment for some direct head-to-head trials has commenced, but final outcomes will not be available until early 2019. Even though cytisine has been recognized for use for smoking cessation since 1964 in Central/Eastern Europe countries, the number of published studies on chemical and clinical properties remained scarce until 2005 based on a Pubmed search (Fig. 2).

\section{Natural sources of cytisine}

Nature has been recognized as a rich source of medicinal alkaloids including cytisine for several thousand years. Plants which contain cytisine have been used in traditional medicine for various purposes e.g. Sophora secundiflora has been used as one of the prehistoric agents with psychotropic activity in North America (33). The alkaloid is derived from the Leguminosae (Fabaceae) family and is most commonly extracted from the Laburnum and Sophora species. Moreover, plant species that contain cytisine are Anagyris, Thermopsis, Cytisus, Genista, Retama, Baptisia and Ulex (34-36). In Europe, the greatest concentration of cytisine is found in the seeds of Laburnum anagyroides (Cytisus laburnum; Golden Rain acacia) (6). Cytisine contents of leaf and seed samples of eight species of the alkaloid rich Sophora family native to New Zealand and Sophora cassioides from Chile have been reported (37). Cytisine is commonly extracted from Sophora family in microphylla (38), tetraptera (39), chathamica (40), fulvida (41), microphylla (42) and Microphylla tetraptera Prostrata (43). Of the alkaloids extracted from the Sophora family, cytisine is among the most abundant, and it has been found that seeds contain the highest concentrations (37). For example, alkaloid concentrations as percent dry mass (\% DM) in the
Sophora microphylla plant increases in the order: $0.02 \%$ in roots, $0.04-0.06 \%$ in the bark, $0.1-0.3 \%$ in leaves and twigs, to $0.4-0.5 \%$ in seeds (37).

\section{Sample extraction procedures from plants}

Cytisine is usually extracted together with other alkaloids and isolation from the alkaloid mixture is necessary (44). Therefore, extraction techniques must allow for assessing detailed chemical composition of alkaloids from different parts of plants such as seeds, rhizomes and plant-derived herbal preparations and from human samples. A simple method for sample preparation is extraction with mixtures of organic solvents or water. The solubility of cytisine in water was found to be $439 \mathrm{~g} / \mathrm{L}$ (45) and cytisine is prone to degradation mainly through oxidation in very high temperatures. In 1933, Klein and colleagues (46) extracted cytisine from powdered seeds in alkali to form a paste. The paste was extracted with chloroform in a Soxhlet apparatus for several hours. Liquid ammonia was also used by Danilchuk to extract cytisine from Thermopsis and Sophora species (47). Wink et al. identified cytisine in several lupine taxa by plant material extraction followed by capillary gas-liquid chromatography and gas chromatography-electron impact mass spectrometry (GC-EIMS) (48). Plant material was homogenized in $\mathrm{HCl}$, centrifuged for $10 \mathrm{~min}$ at $10000 \times \mathrm{g}$, made alkaline by adding ammonia or $\mathrm{NaOH}$ and applied to Extrelut columns (Merck, Darmstadt, Germany). Alkaloids were eluted with $\mathrm{CH}_{2} \mathrm{Cl}_{2}$ and the solvent evaporated in vacuo (48). Song et al. reported separation of 10 alkaloids from Sophora flavescens, Sophora alopecuroides and Sophora tonkinensis via extraction by high-pressure capillary electrophoresis (HPCE) (49). Samples of pulverized Sophora in methanol were placed in volumetric flasks and subject to ultrasonication at room temperature, filtered and analyzed by HPCE (49). In this study, cytisine was only detected in trace amounts in Sophora tonkinensis with a reported limit of detection of $2310 \mu \mathrm{g} / \mathrm{g}$ (49). Ding et al. identified cytisine in 18 herbal preparations of Sophora tonkinensis by extraction followed by HPCE (50). Herbal preparations of Sophora tonkinensis were treated with aqueous ammonia and extracted either with methanol or chloroform and subject to ultrasonication or reflux (50). They found that alkaloid concentrations from the extracts prepared with chloroform followed by ultrasonication or reflux were higher than those obtained using other solvents (50). The amounts of cytisine detected ranged from 0.283-4.234 mg per $\mathrm{g}$ of sample with a reported limit of detection of $5.50 \mu \mathrm{g} / \mathrm{mL}$. Wang et 
al. identified cytisine in Sophora flavescens samples by three different extraction methods: ultrasonic extraction, supercritical water extraction, and accelerated solvent extraction followed by separation by high-pressure capillary electrophoresis equipped with a photodiode array detector (CE-PAD) (51). Out of the extraction methods tested, supercritical water extraction of alkaloids was found to have the highest alkaloid extraction efficiency (51). $\mathrm{Ng}$ et al. identified cytisine in Sophora flavescens herbal preparations by liquid-liquid extraction using a Toxi-tube $A^{\circledR}$ followed by chromatographic separation by high-performance liquid chromatographytandem mass spectrometry (HPLC-MS/MS) (52). McDougal et al. identified cytisine in leaf and seed samples of eight species of Sophora native to New Zealand, and Sophora cassioides from Chile (37). Alkaloids were extracted from dried ground plant tissues by the method of Wink et al. (48) and analyzed by ${ }^{1} \mathrm{H}$ NMR and supported by gas chromatography-mass spectrometry (GC-MS) (37). A summary of alkaloid extraction methods including cytisine identification from plants between 1995-2015 is presented in Table 1.

\section{Detection of cytisine in biological fluids}

Methods for detection and quantification of cytisine in biological fluids such as plasma, serum and urine have been developed recently for applications in forensic toxicology, clinical toxicology and pharmacokinetics. A growing interest in the quantitative determination of cytisine in biological materials such as organs and human body fluids has led to calls for improved analytical analysis. Beyer et al. established a protocol using mixed-mode solidphase extraction of plasma for alkaloid poisoning diagnosis which included the analyte cytisine, followed by HPLC-MS and HPLC-MS/MS (53). The authors reported that HPLC-MS/MS offered greater sensitivity in the detection of alkaloids (53). Pietsch et al. also developed a protocol to diagnose poisoning by alkaloids, including cytisine, in forensic and clinical emergencies by solid-phase extraction followed by HPLC-PDA analysis (54). Musshoff et al.

Table 1. Extraction and identification methods for cytisine from plant material in the scientific literature. The matrices investigated, method of extraction and methods of analysis are described.

\begin{tabular}{|c|c|c|c|c|}
\hline Reference & Matrix & Extraction & Analytical method* & $\begin{array}{c}\text { Limit of cytisine } \\
\text { detection }\end{array}$ \\
\hline $\begin{array}{c}\text { Wink et al. } \\
1995 \\
(46)\end{array}$ & $\begin{array}{l}\text { Plant material } \\
\text { (species of the } \\
\text { Genus Lupinus) }\end{array}$ & $\begin{array}{l}\text { After homogenization } \\
\text { supernatant was alkaline } \\
\text { and alkaloids were } \\
\text { eluted from Extrelut column } \\
\text { with methylene chloride }\end{array}$ & $\begin{array}{c}\text { Gas Chromatograph- } \\
\text { Electron Impact-Mass } \\
\text { Spectrometry GC-EIMS }\end{array}$ & Not Reported \\
\hline $\begin{array}{l}\text { Song et al. } \\
1999 \\
(47)\end{array}$ & Plant material & $\begin{array}{c}\text { Methanol extraction } \\
\text { with } \\
\text { ultrasonication }\end{array}$ & $\begin{array}{c}\text { High-Pressure } \\
\text { Capillary } \\
\text { Electrophoresis HPCE }\end{array}$ & $2.31 \mu \mathrm{g} / \mathrm{g}$ \\
\hline $\begin{array}{l}\text { Ding et al. } \\
2005 \\
(48)\end{array}$ & $\begin{array}{c}\text { Herbal preparations } \\
\text { of } \\
\text { Sophora tonkinensiswith }\end{array}$ & $\begin{array}{l}\text { Chloroform } \\
\text { extraction } \\
\text { ultrasonication }\end{array}$ & $\begin{array}{c}\text { High-Pressure Liquid } \\
\text { Chromatography Photodiode } \\
\text { array detection HPLC-PAD }\end{array}$ & $5.5 \mu \mathrm{g} / \mathrm{mL}$ \\
\hline $\begin{array}{l}\text { Wang et al. } \\
2012 \\
(49)\end{array}$ & $\begin{array}{c}\text { Plant } \\
\text { material } \\
\text { (Sophora flavescens) }\end{array}$ & $\begin{array}{c}\text { Accelerated solvent } \\
\text { extraction and } \\
\text { supercritical water extraction }\end{array}$ & $\begin{array}{c}\text { Capillary Electrophoresis- } \\
\text { Photodiode array } \\
\text { detection CE-PDA }\end{array}$ & $4 \mathrm{ng} / \mathrm{mL}$ \\
\hline $\begin{array}{l}\mathrm{Ng} \text { et al. } \\
2013 \\
(50)\end{array}$ & $\begin{array}{l}\text { Human urine } \\
\text { and plant } \\
\text { material }\end{array}$ & $\begin{array}{l}\text { Liquid-liquid } \\
\text { extraction using a } \\
\text { Toxi-tube } A \circledast\end{array}$ & $\begin{array}{l}\text { High-Pressure Liquid } \\
\text { Chromatography- } \\
\text { Tandem Mass } \\
\text { Spectrometry } \\
\text { HPLC-MS/MS }\end{array}$ & $50 \mathrm{ng} / \mathrm{mL}$ \\
\hline $\begin{array}{l}\text { McDougal } \\
\text { et al. } \\
2015 \\
(35)\end{array}$ & $\begin{array}{l}\text { Eight species of } \\
\text { Sophora native to New } \\
\text { Zealand, and Sophora } \\
\text { cassioides from Chile }\end{array}$ & $\begin{array}{l}\text { After homogenization, } \\
\text { supernatant was made } \\
\text { alkaline and alkaloids } \\
\text { were eluted from } \\
\text { Chem Elut column } \\
\text { with chloroform }\end{array}$ & $\begin{array}{c}\text { Gas Chromatography- } \\
\text { Mass Spectrometry GC-MS }\end{array}$ & $20 \mu \mathrm{g} / \mathrm{mL}$ \\
\hline
\end{tabular}


Table 2. Extraction and identification methods for cytisine from human fluids in the scientific literature. The matrices investigated, method of extraction and methods of analysis are described.

\begin{tabular}{|c|c|c|c|}
\hline Reference & Matrix & Extraction & Analytical method \\
\hline $\begin{array}{l}\text { Beyer at al. } \\
2007 \\
(51)\end{array}$ & Plasma & $\begin{array}{l}\text { Mixed mode solid-phase } \\
\text { extraction followed by } \\
\text { separation on a C8 column }\end{array}$ & $\begin{array}{l}\text { High-Pressure Liquid } \\
\text { Chromatography- } \\
\text { Tandem Mass } \\
\text { Spectrometry } \\
\text { HPLC-MS/MS }\end{array}$ \\
\hline $\begin{array}{l}\text { Pietsch et al. } \\
2008 \\
(52)\end{array}$ & $\begin{array}{l}\text { Human serum } \\
\text { and } \\
\text { urine samples }\end{array}$ & $\begin{array}{c}\text { Solid-phase extraction } \\
\text { CHROMABOND® } \\
\text { C18ec cartridges }\end{array}$ & $\begin{array}{l}\text { High-Pressure Liquid } \\
\text { Chromatography } \\
\text { Photodiode Array } \\
\text { Detection } \\
\text { HPLC-PAD }\end{array}$ \\
\hline $\begin{array}{c}\text { Musshoff et al. } \\
2009 \text { (53) }\end{array}$ & $\begin{array}{l}\text { Human post-mortem } \\
\text { specimens (eg. peripheral } \\
\text { blood, urine, liver, } \\
\text { kidney, bile) }\end{array}$ & $\begin{array}{l}\text { Liquid-liquid or solid } \\
\text { phase extraction } \\
\text { depending on the } \\
\text { biological specimens }\end{array}$ & $\begin{array}{c}\text { Liquid Chromatography } \\
\text { Electrospray } \\
\text { Ionization } \\
\text { Tandem Mass } \\
\text { Spectrometry } \\
\text { LC-ESI-MS/MS }\end{array}$ \\
\hline $\begin{array}{l}\text { Astroug et al. } \\
2010 \\
(54)\end{array}$ & Serum (rabbits) & $\begin{array}{c}\text { Liquid-liquid extraction } \\
\text { (ethyl acetate: } \\
\text { acetonitrile } 1: 1 \mathrm{v} / \mathrm{v})\end{array}$ & $\begin{array}{c}\text { High-Pressure Liquid } \\
\text { Chromatography Ultra Violet } \\
\text { HPLC-UV }\end{array}$ \\
\hline $\begin{array}{c}\text { Jeong et al. } \\
2014 \\
(16)\end{array}$ & Plasma and urine & $\begin{array}{l}\text { Liquid-liquid extraction } \\
\text { (methanol acetonitrile: } \\
\text { formate buffer } 20: 80 \mathrm{v} / \mathrm{v} \text { ) } \\
\text { for plasma samples. } \\
\text { Solid phase extraction } \\
\text { using C18 column } \\
\text { for urine samples }\end{array}$ & $\begin{array}{l}\text { High-Pressure Liquid } \\
\text { Chromatography } \\
\text { Ultra Violet } \\
\text { HPLC-UV } \\
\text { and LC-MS }\end{array}$ \\
\hline $\begin{array}{l}\text { Carlier et al. } \\
2015 \\
(55)\end{array}$ & Blood, urine and or bile & $\begin{array}{c}\text { Solid-phase } \\
\text { extraction } \\
\text { (Oasis@HLB cartridge) }\end{array}$ & $\begin{array}{c}\text { Ultra-High-Pressure } \\
\text { Liquid Chromatography- } \\
\text { Tandem Mass } \\
\text { Spectrometry } \\
\text { UHPLC-MS/MS }\end{array}$ \\
\hline
\end{tabular}

quantified cytisine in post-mortem samples to confirm fatal intoxication caused by ingestion of Cytisus laburnum (55). Amounts of cytisine quantified in the post-mortem samples ranged from $0.3 \mathrm{ng} / \mathrm{g}$ to 4.7 $\mathrm{ng} / \mathrm{g}$ (55). Astroug et al. quantified cytisine by liquidliquid extraction of serum followed by HPLC-UV to study the pharmacokinetics of cytisine in rabbits (56). Jeong et al. quantified cytisine in plasma and urine during a study of single-dose (3 mg orally administered Tabex ${ }^{\circledR}$ ) human pharmacokinetics by LC-MS (17). Interestingly, cytisine was recovered from serum but urine remained unchanged with no metabolites detected (17). Carlier et al. identified cytisine in biological fluids with use of an Oasis ${ }^{\circledR}$ HLB cartridge for separation followed by Ultra-High-Performance Liquid Chromatography-
Tandem Mass Spectrometry UHPLC-MS/MS for the purposes of forensic toxicology (57) (Table 2).

\section{CONCLUSION}

Cytisine, an $\alpha_{4} \beta_{2}$ nAChRs partial agonist, is a plant alkaloid that is commercially extracted for use as a smoking cessation medication. To date, few studies have reported cytisine concentrations in humans following its use as a smoking cessation aid. However, cytisine is gaining in popularity as a smoking cessation aid, and likewise, the number of studies on the development of extraction and identification analytical methodologies have also increased. Cytisine extraction, identification and quantification methods are important to further 
studies that are needed in pharmacokinetics, as well as in toxicology. Improvements in methods of cytisine identification and quantification from plants and biological materials have been made and the number of methodological studies seems to be increasing. Extraction techniques now include ultrasonic extraction, supercritical water extraction, and accelerated solvent extraction. Major technological improvements have been made in respect to techniques involving HPLC, GC-MS and LC-MS which are now indispensable for the early detection and identification of new compounds in crude plant extracts. The development of additional chromatographic techniques that are rapid and do not lead to decomposition, material loss, or artifact formation are needed as there is a wide opportunity for innovation in the purification and detection of cytisine.

\section{Acknowledgments}

Dorota Bartusik-Aebisher acknowledges support from the National Center of Science NCN (New drug delivery systems-MRI study, Grant OPUS-13 number 2017/25/B/ST4/02481).

\section{Conflict of interest}

The authors declare no conflicts of interest.

\section{REFERENCES}

1. http://apps.who.int/iris/bitstream/10665/ 85380/1/ 9789241505871_eng.pdf?ua=1 (accessed on 01. 10.2018).

2. $\mathrm{Ng} \mathrm{M.,} \mathrm{Freeman} \mathrm{M.} \mathrm{K.,} \mathrm{Fleming} \mathrm{T.} \mathrm{D.,}$ Robinson M., Dwyer-Lindgren L. et al.: JAMA 311, 183 (2014).

3. Editorial: Lancet 385, 915 (2015).

4. http://www.clivebates.com/?p=2782\#more2782 (accessed on 01.10.2018).

5. 21 st Century Hazards of Smoking and Benefits of Cessation in the United States. US Department of Health and Human Services FDA, Guidance for industry: bioanalytical method validaton. Center for Drug Evaluation and Research, Centre for Veterinary Medicine, 2001.

6. Tutka P., Zatonski W.: Pharmacol. Rep. 58, 777 (2006).

7. Vinnikov D., Brimkulov N., Burjubaeva A.: J. Smok. Cessat. 3, 57 (2008).

8. Tutka P.: Expert Opin. Investig. Drugs 17, 1473 (2008).
9. Walker N., Howe C., Glover M., McRobbie H., Barnes J.N.V. et al.: New Eng. J. Med. 371, 2353 (2014).

10. Zatonski W., Sulkowska U., Przewozniak K., Zatonski M.: Malignant cancer epidemiology in Poland. In: Potrykowska A., Strzelecki Z., Szymborski J., Witkowski J., Eds. Cancer incidence and mortality versus the demographic situation in Poland. pp 30-49, Governmental Population Council, Warsaw 2014.

11. Coe J.W., Brooks P.R., Vetelino M.G., Wirtz M.C., Arnold E.P. et al.: J. Med. Chem. 48, 3474 (2005).

12. Paduszyńska A., Banach M., Rysz J., Dąbrowa M., Gąsiorek P. et al.: Curr. Pharm. Des. 24, 4413 (2018).

13. Rollema H., Shrikhande A., Ward K.M., Tingley $3^{\text {rd }}$ F.D., Coe J.W. et al.: Brit. J. Pharmacol. 160, 334 (2010).

14. Gonzales D.: JAMA. 296, 47 (2006).

15. Boido C.C., Tasso B., Boido V.F.: Farmaco 58, 265 (2003).

16. Pabreza L.A., Dhawan S., Kellar K.J.: Mol. Pharmacol. 39, 9 (1991).

17. Jeong S.H., Newcombe D., Sheridan J., Tingle M.: Drug Test. Anal. 7, 475 (2015).

18. Jeong S.H., Sheridan J., Newcombe D., Tingle M.: Xenobiotica 48, 1245 (2017).

19. Jeong S.H., Sheridan J., Bullen C., Newcombe D., Walker N., Tingle M.: Xenobiotica, pp. 1-19 (2018).

20. Barlow R.B., McLeod L.J.: Br. J. Pharmacol. 35, 161 (1969).

21. Prochaska J.J., Das S., Benowitz N.L.: BMJ 347, 5198 (2013).

22. Stead L.F., Perrera R., Bullen C., Mant D., Hartmann-Boyce J. et al.: Cochrane Database Syst. Rev. 2012, CD000146.

23. Hajek P., McRobbie H., Myers K.: Thorax 68, 1037 (2013).

24. Tutka P, Zatoński W.: Pharmacol. Rep. 58, 777 (2006).

25. West R., Zatonski W., Cedzynska M., Lewandowska D., Pazik J. et al.: N. Eng. J. Med. 365, 1193 (2011).

26. Leaviss J., Sullivan W., Ren S., Everson-Hock E., Stevenson M. et al.: Health Technol. Assess. 18, 1 (2014).

27. Stapleton J.: BMJ f5736 (2013).

28. Stapleton J., West R.: Nicotine Tob. Res. 14, 463 (2012).

29. https://www.anzctr.org.au/Trial/Registration/ TrialReview .aspx id $=6171 \&$ isClinical $\mathrm{Trial}=\mathrm{Tr}$ ue (accessed on 29.04.2018). 
30. https://www.anzctr.org.au/Trial/Registration/ TrialReview.aspx id=371734\&isReview $=$ true. (accessed on 13.05.2018).

31. https://clinicaltrials.gov/ct2/show/NCT0279 7587? term $=$ cytisine $\&$ cond $=$ smoking $\&$ rank $=5$

32. https://www.york.ac.uk/healthsciences/research/public-health/projects/tb-tobacco/ (accessed on 17.11.2018).

33. Adovasio J.M., Fry G.F.: Econ. Bot. 30, 94 (1976).

34. Marion L., Cockburn W.F.: J. Am. Chem. Soc. 70, 3472 (1948).

35. Maximo P., Lourencüo A.: J. Nat. Prod. 63, 201 (2000).

36. Heenan P.B.: New Zeal. J. Bot. 39, 167 (2001).

37. McDougal O. M., Heenan P. B., Jaksons S., Sansom C. E., Smallfield B.M. et al.: Phytochemistry 118, 9 (2015).

38. Briggs L.H., Ricketts J.: J. Chem. Soc. p. 1795 (1937).

39. Briggs L.H., Taylor W.: J. Chem. Soc. p. 1206 (1938).

40. Briggs L.H., Russell W. E.: J. Chem. Soc. p. 555 (1942)

41. Briggs L.H., Mangan J.: J. Chem. Soc. 70, 1889 (1948).

42. Hoeneisen M., Silva M., Wink M., Crawford D. J., Stuessy T.: Bol. Soc. Chil. Quim. 38, 167 (1993).

43. Peña R.C, Cassels B.K.: Biochem. Syst. Ecol. 24, 725 (1996).
44. Izaddoost M., Harris B.G., Gracy R.W.: J. Pharm. Sci. 565, 352 (1976).

45. Yalkowsky S.H., He Y.P.: Handbook of Aqueous Solubility Data Second Edition. CRC Press, Boca Raton, p. 77, FL 2010.

46. von Klein G.: Handbuch der Pflanzenanalyse, Julius Springer, 1933.

47. Danilchuk D.N.: Uzb. Khim. Zh. 2, 29 (1984).

48. Wink M., Meisner C., Witte L.: Phytochemistry 38, 139 (1997).

49. Song J.Z., Xu H.X., Tian S.J., But P. P.: J. Chromatogr A. 857, 303 (1999).

50. Ding P.L., Yu Y.Q., Chen D.F.: Phytochem. Anal. 16, 257 (2005).

51. Wang H., Lu Y., Chen J., Li J., Liu S.: J. Pharm. Biomed. Anal. 58, 146 (2012).

52. Ng S.W.,Ching C.K., Chan A.Y., Li J., Liu S.J.: Chromatogr. B Analyt. Technol. Biomed. Life Sci. 942, 63 (2013).

53. Beyer J., Peters F.T., Kraemer T., Maurer H.H.: J. Mass. Spectrom. 42, 621 (2007).

54. Pietsch J., Günther J., Henle T., Dressler J.: J. Sep. Sci. 31, 2410 (2008).

55. Musshoff F., Madea B.: Forensic Sci. Int. 186, e1 (2009).

56. Astroug H., Simeonova R., Kassabova L.V., Danchev N., Svinarov D.: Interdiscip. Toxicol. 3, 15 (2010).

57. Carlier J., Guitton J., Romeuf L., Bévalot F., Boyer B.: J. Chromatogr. B Analyt. Technol. Biomed. Life Sci. 975, 65 (2015).

Received: 29.04 .2019 